\title{
Effect of inspiratory pressure support on exercise tolerance and breathlessness in patients with severe stable chronic obstructive pulmonary disease
}

\author{
S E J Keilty, J Ponte, T A Fleming, J Moxham
}

\begin{abstract}
Background - In patients with chronic obstructive pulmonary disease exercise tolerance is commonly limited by breathlessness. These patients have an increased ventilatory load at rest which is exacerbated during exercise. The purpose of this study was to investigate the effect of supporting ventilation by non-invasive inspiratory pressure support (IPS) during submaximal treadmill exercise in such patients to see if they would experience less breathlessness and improve their exercise capacity.
\end{abstract}

Methods - Eight men with disabling breathlessness due to chronic obstructive pulmonary disease (COPD) (mean (SD) FEV $_{1} 0.73(0.2)$ 1) were studied. Patients walked on a treadmill until their sensation of breathlessness, scored at one minute intervals, reached level 5 ("severe") on the 10-point Borg scale. Studies were performed with IPS (mean airway pressure $12-15 \mathrm{~cm} \mathrm{H}_{2} \mathrm{O}$ ), continuous positive airway pressure (CPAP $6 \mathrm{~cm} \mathrm{H} \mathrm{H}_{2}$ ), and with oxygen ( $21 / \mathrm{min}$ via a mask) in random order on three separate days. Each of these walks was compared with a control walk using a sham circuit (breathing air via an oxygen mask at $21 / \mathrm{min}$ from an unlabelled cylinder), and with a baseline walk in which patients walked freely on the treadmill. On cessation of exercise, distance achieved and a leg fatigue score were recorded.

Results - No patients stopped due to leg fatigue, all stopping only when their sensation of breathlessness had reached level 5 on the Borg scale. IPS improved median walking distance by $62 \%$ compared with the control walk (sham circuit). There was no change in walking distance with either CPAP or oxygen at $21 / \mathrm{min}$. There was no difference between the control and the baseline walks.

Conclusions - Inspiratory pressure support can reduce breathlessness and increase exercise tolerance to submaximal treadmill exercise in patients with COPD. This could have implications for the rehabilitation of these severely disabled patients.

(Thorax 1994;49:990-994)

Breathlessness is the most frequent symptom to limit exercise capacity in patients with res- piratory disease. ${ }^{1}$ Exercise limitation associated with extreme dyspnoea frequently occurs well before ventilatory limits are attained. Exercise performance, breathlessness, and arterial blood gas tensions are not closely correlated, so hypoxaemia and hypercapnia are not the sole limiting factors ${ }^{2}$ although they may play a part. $^{3}$ Oxygen has been shown to improve exercise tolerance and ameliorate breathlessness in some patients with pulmonary disease, but not in all instances. ${ }^{4-6}$ Continuous positive airways pressure (CPAP) can also increase exercise tolerance and reduce the sense of breathing effort in patients with chronic obstructive pulmonary disease (COPD), ${ }^{78}$ but not in all cases. ${ }^{9}$

Inspiratory pressure support (IPS) decreases the work of breathing in patients with hyperinflation secondary to airways obstruction when weaning from mechanical ventilation. ${ }^{10}$ Non-invasive assisted ventilation has been shown to reduce breathlessness during acute ventilatory failure resulting from COPD. ${ }^{11}$ These patients have increased loads on the respiratory muscles, particularly during exercise, inducing extreme breathlessness. We hypothesised that the application of non-invasive IPS during exercise may reduce breathlessness and improve exercise tolerance by reducing the load on the respiratory muscles. This hypothesis was tested by measuring the effects of non-invasive IPS by face mask on the tolerance to treadmill exercise in eight patients with stable severe COPD. Walks with IPS were compared with those with oxygen and CPAP.

\section{Methods}

Eight men with stable COPD who complained of disabling breathlessness on exertion were recruited from the chest clinic (age range 60-74 years, mean (SD) $\left.\mathrm{FEV}_{1} 0.73(0.2) 1\right)$.

All patients underwent a period of familiarisation before data collection. This involved several visits to the laboratory where treadmill walks, with and without breathing equipment, were performed so that the patients became completely familiar with the use of the face masks, CPAP, IPS, the Borg scale, and the treadmill. During this training period a comfortable walking speed was found for each patient matching as closely as possible their usual walking speed. Once this had been established, all subsequent walks were performed at this speed. Patients were asked to walk on the treadmill until their perceived rating of 
Table 1 Baseline characteristics of patients

\begin{tabular}{|c|c|c|c|c|c|}
\hline Patient & Age & $F E V_{l}(l)$ & $\begin{array}{l}\mathrm{PaCO}_{2} \\
(\mathrm{kPa})\end{array}$ & $\begin{array}{l}\mathrm{PaO}_{2} \\
(\mathrm{kPa})\end{array}$ & $\mathrm{SaO}_{2}(\%)$ \\
\hline $\begin{array}{l}1 \\
2 \\
3 \\
4 \\
5 \\
6 \\
7 \\
8\end{array}$ & $\begin{array}{l}65 \\
71 \\
64 \\
71 \\
72 \\
74 \\
66 \\
60\end{array}$ & $\begin{array}{l}1.0 \\
0.8 \\
0.9 \\
0.4 \\
0.7 \\
0.6 \\
0.9 \\
0.5\end{array}$ & $\begin{array}{l}5 \cdot 4 \\
4 \cdot 3 \\
5 \cdot 3 \\
5 \cdot 5 \\
5 \cdot 6 \\
4 \cdot 9 \\
6.9 \\
6.0\end{array}$ & $\begin{array}{l}8 \cdot 7 \\
9 \cdot 5 \\
7 \cdot 9 \\
7 \cdot 0 \\
5 \cdot 3 \\
8 \cdot 4 \\
7 \cdot 0 \\
9 \cdot 7\end{array}$ & $\begin{array}{l}93 \\
95 \\
92 \\
90 \\
75 \\
95 \\
86 \\
94\end{array}$ \\
\hline Mean (SD) & $68(6)$ & $0.73(0.2)$ & $5.5(0.76)$ & $7 \cdot 9(1.5)$ & $90(6 \cdot 8)$ \\
\hline
\end{tabular}

$\mathrm{FEV}_{1}=$ forced expiratory volume in one second; $\mathrm{PaO}_{2}, \mathrm{PaCO}_{2}=$ partial pressure of oxygen and carbon dioxide (earlobe sample); $\mathrm{SaO}_{2}=$ oxygen saturation.

breathlessness had reached level 5 ("severe") on the 10-point Borg scale. ${ }^{12}$ For three patients who were not sufficiently breathless walking on the flat, a gradient was used.

When patients were familiar with the laboratory routine, data were collected on three separate days. The study consisted of walking with a different mode of respiratory support on each day: IPS, CPAP, or oxygen at $21 / \mathrm{min}$. These were compared with two other treadmill walks on each occasion: a baseline walk (walking freely on the treadmill) and a control walk using a "sham" gas delivery system - breathing air from an unlabelled cylinder at $21 / \mathrm{min}$. All patients experienced all conditions. The tests were performed in random order and each walk was preceded by at least 30 minutes rest. No more than three days elapsed between study visits. No patients had had a recent exacerbation of their disease or a change in their medication over the study period.

Non-invasive inspiratory pressure support was applied using a pressure cycled ventilator ("NIPPY", Thomas Respiratory Systems, London, UK) with the inspiratory pressure set for patient comfort (range $12-15 \mathrm{~cm} \mathrm{H}_{2} \mathrm{O}$ ). All breaths were patient triggered (threshold $0.5 \mathrm{~cm} \mathrm{H}_{2} \mathrm{O}$ ) and applied to the patients' airway via a full face mask held in position by a Velcro head strap. To apply CPAP a "BiPAP" ventilatory support system (Respironics Inc, Murrysville, Pennsylvania, USA) was used with the inspiratory and expiratory positive airway pressure dials set to achieve $6 \mathrm{~cm} \mathrm{H}_{2} \mathrm{O}$, maintaining a positive pressure throughout the respiratory cycle, via a full face mask. The oxygen and control (air) walks were performed with a standard oxygen mask (Intersurgical Ltd, Wokingham, UK) with a gas flow of $21 / \mathrm{min}$ from unlabelled cylinders.

\section{MEASUREMENTS}

On each visit baseline measurements were made to establish that patients were stable. Forced expiratory volume in one second $\left(\mathrm{FEV}_{1}\right)$ and vital capacity (VC) were recorded using a dry wedge bellows spirometer (Vitalograph Ltd, Buckinghamshire, UK), and resting blood gas tensions were measured from an arterialised earlobe sample. ${ }^{1314}$ The $\mathrm{PaO}_{2}$ and $\mathrm{PaCO}_{2}$ from this sample served to calibrate the transcutaneous blood gas monitoring equipment.

During exercise transcutaneous partial pressure of oxygen $\left(\mathrm{TcPO}_{2}\right)$ and carbon dioxide $\left(\mathrm{TcPCO}_{2}\right)$ using a combined electrode (Radiometer Ltd, Copenhagen, Denmark) were monitored continuously, as were oxygen saturation $\left(\mathrm{SaO}_{2}\right)$ and heart rate by pulse oximetry (Ohmeda Ltd). These were recorded at one minute intervals during exercise. At one minute intervals patients were also asked their perceived breathlessness rating which they communicated by pointing to a number or phrase on the Borg scale set in large type on a sheet in front of them. The treadmill was stopped when the patient had reached level 5 (severe) on the Borg scale.

On cessation of exercise the distance achieved and duration of exercise were recorded, together with a Borg score for leg fatigue.

\section{DATA ANALYSIS}

All data were analysed using a statistical computer software package (Minitab Inc, Pennsylvania, USA). The percentage change in median walking distance achieved with respiratory intervention was compared with baseline and control walks for each visit using the Wilcoxon signed rank test for non-parametric data.

\section{Results}

All patients completed all parts of the study. Table 1 shows the baseline measurements of the patients. No patient stopped walking due to leg fatigue, only stopping when the perceived breathlessness rating had reached level 5 (severe). Table 2 shows the walking distance achieved in each case. Figure 1 shows the effect of IPS on exercise tolerance compared with the

Table 2 Individual walking distances achieved and percentage change in walking distance between control walks and walks with inspiratory pressure support (IPS), oxygen at 2 llmin, and continuous positive airway pressure (CPAP)

\begin{tabular}{|c|c|c|c|c|c|c|c|c|c|}
\hline \multirow{2}{*}{$\begin{array}{l}\text { Patient } \\
\text { no. }\end{array}$} & \multicolumn{3}{|l|}{ IPS } & \multicolumn{3}{|l|}{ Oxygen } & \multicolumn{3}{|l|}{ CPAP } \\
\hline & $\begin{array}{l}\text { Control } \\
\text { distance } \\
(m)\end{array}$ & $\begin{array}{l}\text { IPS } \\
\text { distance } \\
(m)\end{array}$ & $\begin{array}{l}\% \text { change } \\
\text { from control } \\
\text { to IPS }\end{array}$ & $\begin{array}{l}\text { Control } \\
\text { distance } \\
\text { (m) }\end{array}$ & $\begin{array}{l}\text { Oxygen } \\
\text { distance } \\
\text { (m) }\end{array}$ & $\begin{array}{l}\% \text { change } \\
\text { from } \\
\text { control to } \\
\text { oxygen }\end{array}$ & $\begin{array}{l}\text { Control } \\
\text { distance } \\
\text { (m) }\end{array}$ & $\begin{array}{l}\text { CPAP } \\
\text { distance } \\
(m)\end{array}$ & $\begin{array}{l}\% \text { change } \\
\text { from } \\
\text { control to } \\
\text { CPAP }\end{array}$ \\
\hline $\begin{array}{l}1 \\
2 \\
3 \\
4 \\
5 \\
6 \\
7 \\
8\end{array}$ & $\begin{array}{r}311 \\
183 \\
707 \\
83 \\
22 \\
344 \\
192 \\
132\end{array}$ & $\begin{array}{r}410 \\
421 \\
743 \\
262 \\
36 \\
877 \\
241 \\
213\end{array}$ & $\begin{array}{r}32 \% \\
130 \% \\
5 \% \\
216 \% \\
64 \% \\
155 \% \\
26 \% \\
61 \%\end{array}$ & $\begin{array}{r}371 \\
206 \\
613 \\
57 \\
24 \\
566 \\
242 \\
118\end{array}$ & $\begin{array}{r}410 \\
173 \\
424 \\
204 \\
27 \\
446 \\
275 \\
131\end{array}$ & $\begin{aligned} & 11 \% \\
- & 16 \% \\
- & 31 \% \\
+ & 258 \% \\
+ & 13 \% \\
- & 21 \% \\
+ & 14 \% \\
+ & 11 \%\end{aligned}$ & $\begin{array}{r}254 \\
118 \\
384 \\
54 \\
27 \\
381 \\
186 \\
100\end{array}$ & $\begin{array}{r}182 \\
95 \\
217 \\
76 \\
14 \\
125 \\
132 \\
117\end{array}$ & $\begin{array}{l}-28 \% \\
-19 \% \\
-43 \% \\
+41 \% \\
-48 \% \\
-67 \% \\
-29 \% \\
+17 \%\end{array}$ \\
\hline $\begin{array}{l}\text { Median } \\
\text { (SD) }\end{array}$ & $187.5(215)$ & $336(282)$ & $62.3(73.4) \% *$ & $224(220 \cdot 8)$ & $239.5(153.9)$ & $11(94 \cdot 5) \%$ & $152(138)$ & $121(62 \cdot 4)$ & $1.5(42) \%$ \\
\hline
\end{tabular}




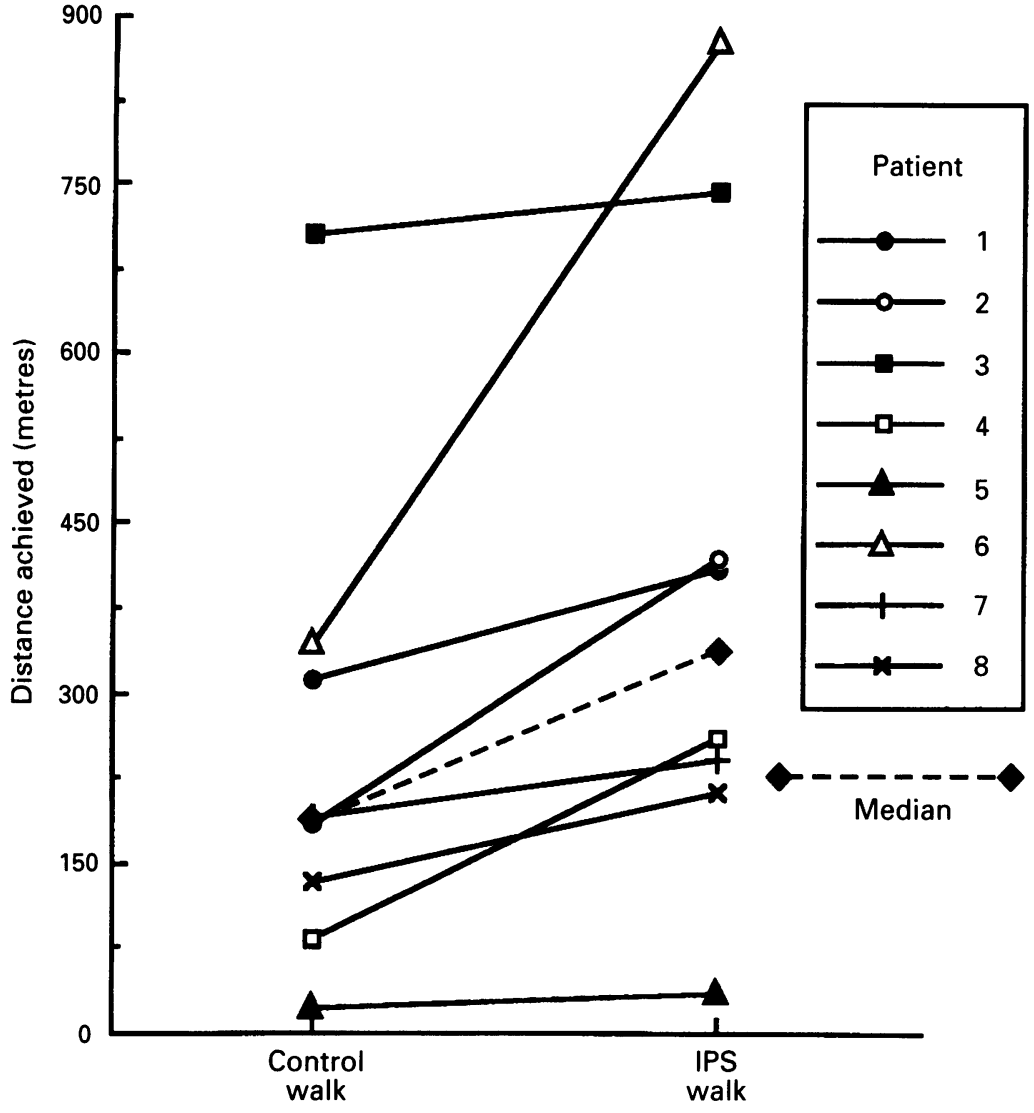

Figure 1 Walking distances achieved on the control walk (breathing air via a face mask from an unlabelled cylinder) and with inspiratory pressure support (IPS). $p=0.01$.

control walk. IPS improved median walking distance by $62 \%(90 \mathrm{~m}$, range $+14 \mathrm{~m}$ to $+533 \mathrm{~m}$ ) when compared with the control walk $(p=0.01)$. On each occasion the control walk (using the sham system) was compared with the baseline walk. There was no difference in walking distance achieved between the baseline and control walks. No significant change in walking distance occurred with either oxygen at $2 \mathrm{l} / \mathrm{min}$ or CPAP at $6 \mathrm{~cm} \mathrm{H}_{2} \mathrm{O}$.

Dyspnoea ratings during the walks with IPS were lower than those during control walks. Figure 2 shows the perceived sensation of breathlessness (Borg scale) plotted against time (minutes) during IPS assisted walking compared with the control walk for each patient.

At the end of the control walk patients showed a mean fall in oxygen saturation of $6 \%$ (range $1-11 \%$ ). Table 3 shows the mean changes in blood gas measurements on cessation of exercise with respiratory intervention compared with resting values breathing room air. Walking with oxygen (at $2 \mathrm{l} / \mathrm{min}$ ) increased the mean oxygen saturation by $6 \%$ (range 4 $12 \%)$ at the end of exercise compared with resting values breathing air, but this did not ameliorate breathlessness or improve exercise capacity. Walking with IPS improved mean $\mathrm{SaO}_{2}$ by only $3 \%$ (range $1-9 \%$ ), but patients reported feeling less breathless and were able to walk further.

\section{Discussion}

The application of inspiratory pressure support during treadmill exercise significantly improved exercise capacity and reduced the sensation of breathlessness in patients with severe stable COPD. The improvement varied between the eight patients, some increasing their endurance slightly and others more than doubling the distance walked. The control walk demonstrated that this was unlikely to be a placebo effect, although it was not possible to give true "sham" IPS. Neither oxygen at $21 / \mathrm{min}$ nor $\mathrm{CPAP}$ at $6 \mathrm{~cm} \mathrm{H}_{2} \mathrm{O}$ significantly improved exercise capacity in this patient group.

Patients with COPD have an increased ventilatory load at rest which worsens on exercise, partly as a result of dynamic hyperinflation and, as a consequence, tidal breathing occurs on the flatter, less compliant part of the pressurevolume curve. Prolongation of expiration may also lead to inspiration beginning before functional residual capacity (FRC) is reached, which may cause positive end expiratory pressure generation (intrinsic PEEP). ${ }^{1516}$ The inspiratory muscles have to generate an inspiratory pressure sufficient to overcome intrinsic PEEP before airflow can begin and this creates an inspiratory threshold load which increases the work of breathing. The increased work of breathing in patients with COPD is borne mainly by the inspiratory muscles - that is, the diaphragm, external intercostal, and accessory muscles. Inspiratory muscle function, however, can be severely impaired in these patients. Changes in the geometry and configuration of the chest wall and diaphragm alter the mechanics of breathing and impair diaphragmatic function. Hyperinflation causes muscle shortening and, during exercise, progressive dynamic hyperinflation causes further shortening of inspiratory muscles. The increased ventilation associated with exercise also causes an increase in the velocity of shortening of the inspiratory muscles. As maximal force is inversely proportional to the velocity of contraction, inspiratory muscle capacity is reduced. When ventilatory load is high and ventilatory capacity is reduced, feedback from the excessively stressed respiratory muscles to the central nervous system is perceived as a great sense of breathing effort or the unpleasant sensation of breathlessness. ${ }^{17}$ Our hypothesis is that exercise is limited by breathlessness which is in itself largely due to excessive work of breathing. Further studies investigating the extent to which the work of breathing is reduced by IPS, and the relation between the extent of load reduction and endurance, would be of interest.

CPAP, whilst aiding inspiration, may add to the expiratory load and may increase the sense of respiratory effort. In this study $6 \mathrm{~cm} \mathrm{H}_{2} \mathrm{O}$ CPAP was applied. Most studies of the effect of CPAP on exercise have applied levels of $5-10 \mathrm{~cm} \mathrm{H}_{2} \mathrm{O}^{7-9}$ During exercise intrinsic PEEP frequently increases and, to offset this, it would be ideal if PEEP could be progressively raised. However, high levels of PEEP impose a substantial expiratory load.

In our study of eight patients, all of whom were hypoxic at rest and desaturated on their control walk, oxygen at $2 \mathrm{l} / \mathrm{min}$ did not improve exercise performance despite a mean improvement in $\mathrm{SaO}_{2}$ of $6 \%$ on cessation of ex- 
Table 3 Mean (range) changes in blood gas measurements on cessation of exercise ("severely breathless") compared with resting values breathing room air

\begin{tabular}{llll}
\hline Respiratory intervention & $\% \mathrm{SaO}_{2}$ (oximeter) & Transcutaneous $\mathrm{PO}_{2}(\mathrm{kPa})$ & Transcutaneous $\mathrm{PCO}(\mathrm{kPa})$ \\
\hline Control walk & $-6 \%(-1 \%$ to $-11 \%)$ & $-1 \cdot 3(-3 \cdot 6$ to $+0 \cdot 4)$ & $+0 \cdot 4(+0 \cdot 3$ to $+0 \cdot 9)$ \\
Inspiratory pressure support & $+3 \%(+1 \%$ to $+9 \%)$ & $+0 \cdot 8(-0.4$ to $+2 \cdot 5)$ & $-0 \cdot 3(-1 \cdot 2$ to $-2 \cdot 3)$ \\
Oxygen $(2 \mathrm{l} / \mathrm{min})$ & $+6 \%(+4 \%$ to $+12 \%)$ & $+3 \cdot 7(+1 \cdot 6$ to $+9 \cdot 5)$ & $+0 \cdot 04(-1 \cdot 7$ to $+0 \cdot 5)$ \\
$\mathrm{CPAP}\left(6 \mathrm{~cm} \mathrm{H} \mathrm{H}_{2} \mathrm{O}\right)$ & $-2 \%(+6 \%$ to $-22 \%)$ & $+0 \cdot 1(-0.8$ to $+0 \cdot 8)$ & $+0 \cdot 3(-0 \cdot 8$ to $+1 \cdot 0)$ \\
\hline
\end{tabular}

Patient 1

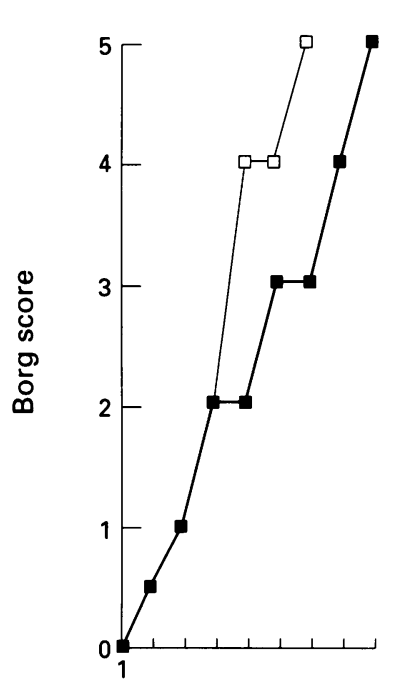

Patient 5

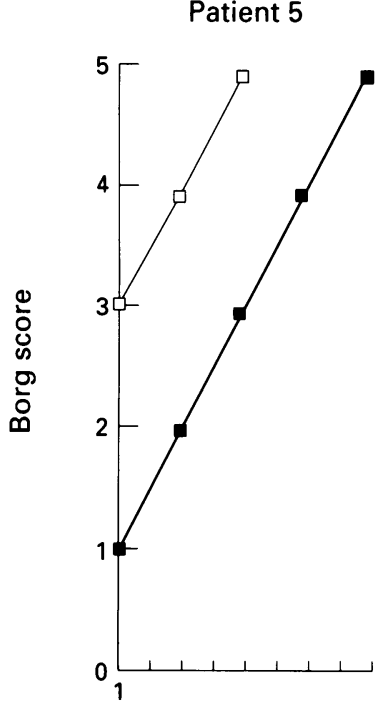

Patient 2
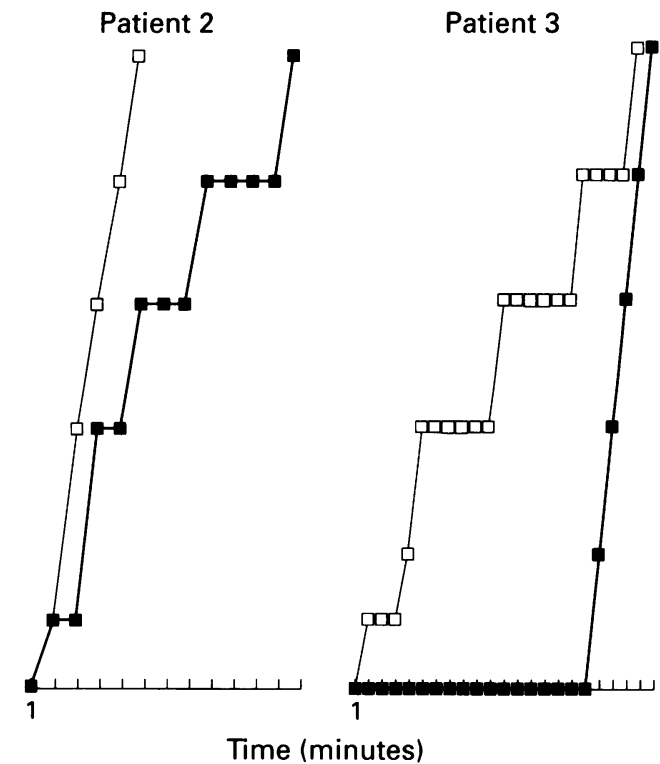

Patient 7

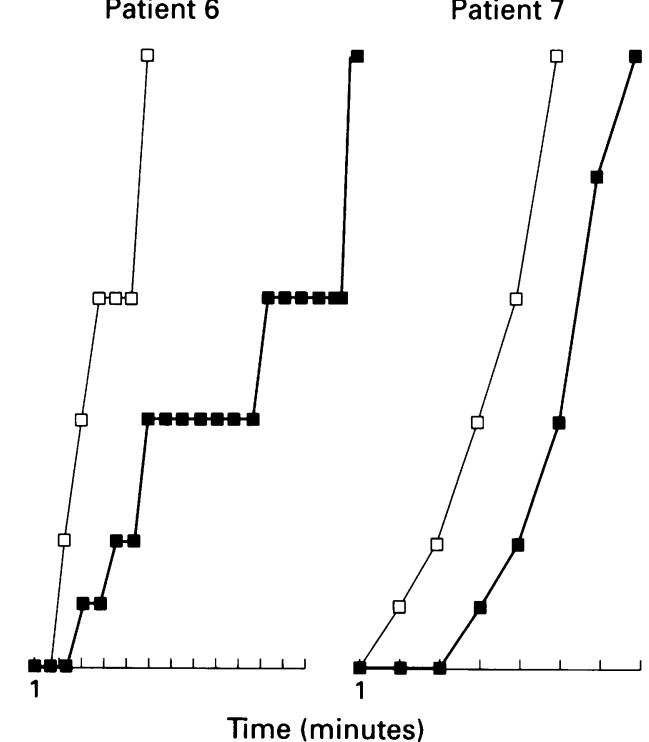

Patient 4
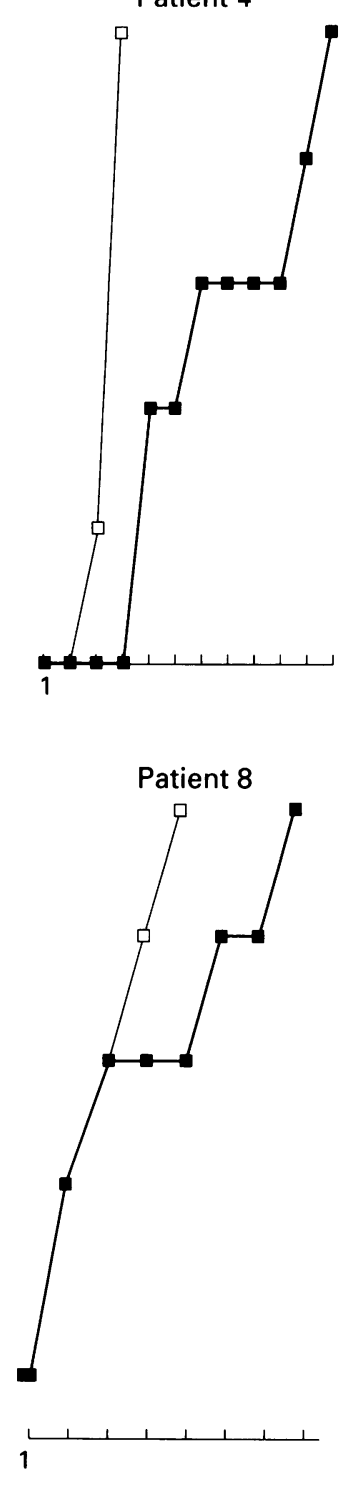

Figure 2 Relation between breathlessness (Borg scores) and duration of exercise (time) for each patient with inspiratory pressure support (IPS) ( $-\square$ compared with the control walk ( $\square-\square$ ). In each case patients reported being less breathless walking with IPS than at iso-time during the control walk.

ercise compared with resting values. Oxygen at higher flow rates would have been unlikely to reduce breathlessness or increase endurance.

Breathlessness, or fear of breathlessness on exertion, is an important factor limiting activity in patients with COPD. ${ }^{18}$ Inactivity reduces the efficiency of skeletal muscle and impairs cardiovascular function. If IPS could allow higher levels of exercise, it could conceivably play a key part in pulmonary rehabilitation and enhance exercise capacity as well as achieving short term symptom control. If ventilation can be supported during exercise and greater distances can be achieved, this will improve cardiovascular performance and increase the metabolic efficiency of limb muscle, thereby reducing the ventilatory requirement for a given level of exercise.

The optimal settings of airway pressure need to be investigated so that IPS can be tailored to the requirements of individual patients. The feasibility of portable equipment, for use by patients at home and in the community, needs to be explored. Portable and domiciliary IPS could mitigate against the disability of severe breathlessness, enabling patients to perform everyday tasks previously made impossible by dyspnoea. Continuing studies of IPS in patients with severe respiratory disease may contribute significantly to the understanding of the mech- 
anisms of breathlessness, and may facilitate the mobility and rehabilitation of these severely disabled people.

1 Rampulla C, Baiocci S, Dacasto E, Ambrosino N. Dyspnea on exercise - pathophysiological mechanisms. Chest 1993 101(Suppl):248-52s.

2 Swinburn CR, Wakefield JM, Jones PW. Relationship between ventilation and breathlessness during exercise in chronic obstructive airways disease is not altered by prevention of hypoxaemia. Clin Sci 1984;67:515-9.

3 Lane R, Cockcroft A, Adams L, Guz A. Arterial oxygen saturation and breathlessness in patients with chronic saturation and breathlessness in patients with chron

4 Waterhouse JC, Howard P. Breathlessness and portable oxygen in chronic obstructive airways disease. Thorax 1983;38:302-6

5 Lock SH, Paul EA, Rudd RM, Wedzicha JA. Portable oxygen: assessment and usage. Respir Med 1991;85:40712.

6 Mak VHF, Bugler JR, Roberts CM, Spiro SG. Effect of arterial oxygen desaturation on six minute walk distance, perceived effort and perceived breathlessness in patients with airflow limitation. Thorax 1993;48:33-8.

7 O'Donnell DE, Sanii R, Younes M. Improvement in exercise endurance in patients with chronic airflow limitation using continuous positive airway pressure. Am Rev Respir Dis $1988 ; 138: 1510-4$

8 O'Donnell De, Sanii R, Giesbrecht G, Younes M. Effect of continuous positive airway pressure on respiratory sensation in patients with chronic obstructive pulmonary disease during submaximal exercise. Am Rev Respir Dis 1988;138: 1185-91.
9 Petrov BJ, Enoardo C, Gottfried BJ. Effect of CPAP on respiratory effort and dyspnea during exercise in severe COPD $f$ Appl Physiol 1990;69:179-88.

10 Brochard L, Harf A, Lorino H, Lemaire F. Inspiratory pressure support prevents diaphragmatic fatigue during weaning from mechanical ventilation. Am Rev Respir Dis 1989;139:513-21.

11 Bott J, Carroll MP, Conway JH, Keilty SEJ, Ward EM Brown AM, et al. Randomised controlled trial of nasa ventilation in acute ventilatory failure due to chronic obstructive airways disease. Lancet 1993;341:1555-7.

12 Borg GAV. Psychophysical basis of perceived exertion. Med Sci Sports Exerc 1992;14:377-81.

13 Spiro SG, Dowdeswell IRG. Arterialised earlobe samples for blood gas tensions. $B r \mathcal{F}$ Dis Chest 1976;70:263-8.

14 Godfrey S, Wozniak ER, Courtenay-Evans RJ, Samuels CS. Earlobe blood samples for blood gas analysis at rest and during exercise. $B r$ F Dis Chest 1971;65:58-64.

15 Gottfried SB, Rossi A, Higgs BD, Calverley PMA, Zocchi , Bozic C, et al. Non-invasive determination of respirator system mechanics during mechanical ventilation for acute respiratory failure. Am Rev Respir Dis 1985;131:414-20.

16 Rossi A, Gottfried SB, Higgs BD, Lennox S, Calverley PMA, Beglin P, et al. Measurement of the static compliance of the total respiratory system in patients with acute respiratory failure during mechanical ventilation. The respiratory failure during mechanical ventilation. The Respir Dis 1985;131:672-7.

17 Moxham J. Respiratory muscle fatigue: central, peripheral or both? In: Jones NL, Killian KJ, eds. Breathlessness. The Campbell Symposium, 16-19 May 1991, McMaster University, Hamilton, Ontario, Canada. (Distributed by Boehringer Inglheim, Canada). 1992:45-51.

18 Miller FW. Useful methods of therapy. Chest 1971;60 (Suppl):s2-5. 